\title{
Grand Rounds Panel Discussion: Provider Payment Reform: Past, Present, and Future
}

Neha Bansal Etherington, MD, Shuwei Wang, MD, Debbie Chen, MD, Anita Modi, MD, and Jad AlDanaf, MD

\section{PANELISTS}

Gregory C. Kane, MD, FACP

The Jane and Leonard Korman, Professor and

Chairman, Department of Medicine

David B. Nash, MD, MBA

The Dr Raymond C and Doris N Grandon

Professor, and Dean of the Jefferson College of

Population Health

Rhea E. Powell, MD, MPH

Assistant Professor of Medicine

Rachel B. Sorokin, MD, FACP

Associate Professor of Medicine and Medical

Director of Safety and Quality

Lawrence D. Ward, MD, MPH

Associate Professor of Medicine and Vice Chairman

for Clinical Practice and Quality

\section{INTRODUCTION}

The impetus for provider payment reform in healthcare grew out of the recognition that growth in healthcare spending in the United States has been unsustainable and that despite this, the United States has not achieved better health for its population when compared to other developed nations. ${ }^{1}$ Numerous factors have been identified as potentially contributing to burgeoning healthcare spending, including inadequate primary care and avoidable complications of care. ${ }^{2}$ Among these factors targeted for reform was the fee-for-service payment structure in healthcare which was thought to incentivize more care rather than better care..$^{3-4}$ In this context, the Affordable Care Act (ACA) was passed in 2010 not only to expand access to care, but also to redirect Centers for Medicare and Medicaid (CMS) reimbursements for healthcare services and to address the growing demand to curb healthcare spending by rewarding value over volume. Following the ACA, the Medicare Access and CHIP Reauthorization Act (MACRA) was passed in 2015 to repeal the Sustainable Growth Rate formula and to expand the scope of value-based payment structures in healthcare. ${ }^{5}$
The ACA implemented four programs that addressed provider payment reform: the Hospital Readmissions Reduction Program (HRRP), the Hospital Acquired Condition Reduction Program (HAC), the Value Based Purchasing Program (VBPP) and the Value Modifier Program (VM). HRRP applies a financial penalty to hospitals for 30-day readmission rates that exceed national averages for specific conditions such as heart failure and pneumonia. Upon its inception, many within the healthcare industry expressed concern that by design HRRP may unfairly penalize safety net hospitals that care for a greater proportion of low-income and low-literacy patients who are at a higher risk for readmission. However, early studies have shown that low-performing hospitals and specifically low-performing safety net hospitals have reduced their readmission rates proportionately more since program implementation, reducing disparities between hospitals. ${ }^{6-7}$ HAC expands on the Hospital Acquired Conditions Initiative which withheld incremental payment for eight hospital acquired conditions and was found to be associated with reduced rates of central line-associated bloodstream infections (CLABSIs) and catheter-associated urinary tract infections (CAUTIS). ${ }^{8}$ HAC builds on the progress made by this program by applying an additional financial penalty to hospitals ranking in the bottom quartile for rates of hospital acquired conditions. VBPP quantifies high quality care based on five domains: processes of care, clinical outcomes, patient experience of care, patient safety, and cost of care. These metrics are compiled into a total performance score based on which hospital reimbursements are adjusted up or down. This program aligned incentives with the existing Physician Quality Reporting System (PQRS) for reporting quality metrics, increasing transparency and public availability of data through mediums like Hospital Compare. ${ }^{9}$

MACRA subsequently created two pathways for provider reimbursement: the Merit Based Incentive Payment System (MIPS) and Alternative Payment Models (APMs). MIPS is rooted in the traditional fee-for-service payment structure and consolidates several previously existing programs including the Value Modifier Program. MIPS quantifies value based on a weighted performance score that includes quality of care, resource utilization, meaningful use of electronic health records and clinical practice improvement. Providers will receive bonuses or penalties ranging from $4 \%$ in 2019 to $9 \%$ in 2022 based on performance. APMs are payment models that in order to qualify under MACRA require providers to bear more than nominal financial risk. 
In 2015, Medicare set the goal that by the end of 2018,90\% of fee-for-service payments would be tied to quality or value and $50 \%$ of payments would be tied to quality or value through alternative payment models. ${ }^{10}$

The environment in healthcare is changing, and this brings with it serious challenges but also exciting opportunities to improve the way physicians practice medicine. The following is a transcript of our experts as they discuss the effect of provider payment reform on clinical practice as well as strategies for continuing to provide effective patient care in a changing healthcare environment.

\section{TRANSCRIPT}

Neha: A lot of these programs are designed to incentivize us as providers to improve the way we deliver care, to be more effective at delivering evidence-based, high-value care. How have you seen this play out over the past five years? How have you seen this influence the way we practice medicine?

Dr. Kane: I'll go ahead and jump in first. A core way that I've seen this is through the transparency of our data recording and I'm just going to use Primary Care as a stepping stone here-Dr. Powell and Dr. Ward may be able to amplify what I'm about to comment on. Our providers in our Primary Care practices now know where they rank in terms of vaccination rates, colon cancer screening rates, mammography rates-things that are really of intrinsic value to healthcare and to our population. What I think we need to ultimately do, Neha, is move towards true effective payments for the physicians who are really doing an exemplary job meeting those goals. We're very fortunate that we've got a superlative faculty in Internal Medicine who are taking great care of patients, but my bet is that if you ask a doctor on the street, "How much is this making a difference in your annual salary, in your day-to-day life?" they may not think it necessarily has that big of an impact in terms of tangible outcomes. We need to continue to move in that direction because if we're going to be ready by 2018 to have that large of our revenue based on quality, we've really got to be incentivizing our physicians to move at that level. But the good news is our faculty is well-aware of the quality imperative. They have the availably of data for their own practices and we're beginning to build on this incrementally. I would say to you I'm frustrated that we're moving too slowly and as an organization, we have to really accelerate our pace of change.

Dr. Powell: I can speak to my experience, my [institutional] memory is a little bit shorter. I've been at Jefferson now almost five years, practicing here post-Affordable Care Act, and I practice largely in the outpatient setting in Primary Care. I think the biggest difference I've seen evolving and continuing to evolve is the role of the team in providing care as opposed to the physician being the main person interacting with the patient. The reimbursement models are shifting to support the team to be an integral part of that. We have a care coordinator now in our practice, and one of my patients said it best: "Well I can never get you on the phone but I can always get Paula on the phone. She knows what's going on and I know she can get you on the phone." And it's not just that they can be accessible but they bring expertise that I don't have on community resources, on how to get patients plugged in with visiting nurses, with food resources that they need. In my experience, that's been one of the biggest changes that I have seen.

Dr. Sorokin: I'm going to take the inpatient part which is the part that I know well. Since the Affordable Care Act, we've had an increased proportion of our payments be subject to penalty. At the moment it's $6 \%--a 6 \%$ withhold. If you think about what the margin is for non-profit hospitals, they generally run 1-4\%. More than your margin is being withheld by Medicare. So how does that change the work that we're doing? What's happened on the inpatient side is that there's also a much stronger team and multidisciplinary process to treatment. Take, for example, the hospital-associated infections. There are six that occur both in the value-based purchasing program and the hospital-associated conditions program. If you'd like to know what top decile performance is across the country, it is zero. That gives you a sense of what's been happening nationally. We have working groups and most of you are familiar with the fact that we have very standard protocols for line infections. In fact, we have had quite a good rate of central line infections-a 75\% drop-similar to rates across the country and that's true across the country and that tells you how fast people are improving the care that they deliver. We have had dramatic drops over the last few years in our rates of CAUTIs. We have plenty of work to do for C.diff and you know that we're doing huddles now and we appreciate your support. Each one of those has a network of doctors and nurses co-leading teams to think through how to improve our processes so that as a group, as an institution, we deliver more reliable care to patients. I'd say that's a fairly large change in how we approach our work, and that's a direct outgrowth of us thinking differently about what it means to take care of a patient. Is it really one person taking care of the patient, or is it really the institution and the quality of the processes we provide from intake in the Emergency Room or Direct Admission on to discharge and potential readmission? That's a large feat.

Dr. Ward: I think one of the things that I've seen in the last five years at an institutional level-not just at Jefferson, but across the country-is a different appreciation for primary care involvement the community, a different way of thinking in terms of population. And this requires a different approach. How do we draw people into primary care? I think this is starting to affect and draw attention to 
subspecialists. If we really want to change and influence costs, procedures and things are really being done by subspecialists. I've seen an appreciation for primary care and the need for a team, as well as the need to train people differently to operate as a leader of a team. This is affecting residencies and fellowship programs. It's hasn't changed yet in terms of compensation to get a stampede of people going into primary care, but it's already started to affect primary care significantly and will affect subspecialties more. At Jefferson, we've seen the need to work as a team with our family practice colleagues in the outpatient setting and the hospital because we're looking at everything now. Care doesn't stop when patients get discharged from the hospital. It doesn't stop when they get admitted to the hospital. To improve cost and quality, we have to look at the continuum.

Dr. Nash: First, I'm an avid reader of the Medicine Forum. I can offer a bit of national perspective. Themes I heard here: teamwork, care coordination, accountability, and transparency. The paradox? For doctors, focusing of cost and finance problems is never the way to fix cost and finance problems. The only way to fix these challenges is with the great answers we've heard here: teamwork, transparency, care coordination, and accountability. No one has ever measured what I've done as an outpatient physician or given me non-punitive feedback on my performance, but it will be these paradigm changes that make it work.

Neha: A couple of you have mentioned this issue of transparency, and I know people can now look up their doctors online. What role has this played in the delivery of patient care?

Dr. Kane: I think the first and traditional response that physicians have to data is that the data is not correct. "My patients in Center City, Philadelphia are much more complicated." We need to get beyond that and get to a place where we're embracing the data. At the same time, there is a valid point in making sure that the data is accurately corrected for complexity. I do know of some sophisticated practices that have PR firms responsible for wiping the data off the screen, flooding bad reviews with positive reviews. But I think "hospital compare" will become more of the norm, and we're ready and excited for that. We're happy to use the data.

Dr. Nash: I concur. The search evidence about who uses that information is actually not intuitive. Does anyone out there besides us go to the website? Consumers are incredibly confused about all of this. Most of them have never heard of it. We can't fool ourselves into thinking that the public pays any attention to this at all. Their opinions about individual doctors and hospitals stem from 1. Family, 2. Friends, and 3. What they read on the internet-and it's not CMS.gov. I think the severity adjustment is really important. Hospitals like Jefferson do get penalized because social determinants are messier with some of our patients. Maybe they don't have a place to go, maybe they can't afford their medications, maybe they don't have a ride to go back to the doctor. Most avid readers of the report cards are the delivery systems themselves. It's a pretty competitive market, this town. So those are the people who pay the most astute attention.

Dr. Sorokin: The other purpose of transparency is for physicians themselves. It doesn't even have to make it public. Even internally, we have a pretty motivated crew of caregivers who are driven to improve their own practice of medicine with the appropriate feedback. To give you an example, Pittsburgh chose to make HCAHPs data available for each physician. They didn't plan any interventions, they just made the data available. And their numbers improvedthe physicians did it themselves. If you've never been measured, you don't know where you are.

Dr. Ward: If you've ever Googled yourself, HealthGrades sometimes comes up and people have said they've found me through that. I put a personal statement online, and the majority of my patients tell me they were looking through the website and one of the reasons they came to me was based on my philosophy on medicine. I think change is inevitable. I agree that a lot of the way we've done it in the past has been with individual providers noticing, "My practice is lower than yours in this metric," and that's driven a lot of change. Quality improvement is great-not by penalizing, not by incentivizing, but just by putting people's numbers up there. The pendulum of medicine swings all the time; doctors are feeling over-measured and wonder if that really does improve care. Does a flu shot actually stop people from going into the hospital or dying? We should be moving more towards outcomes, but we can't have too many outcomes if these measurements are just making our lives miserable and not really improving patient care. If we're collecting data on many things and nothing's really useful, that's where we're going to get pushback. We have to be careful about selecting some outcomes that the doctors and their teams can have some improvement over. We don't have that nailed down yet, but that's what we need to work towards.

Dr. Nash: That's a great point, and in my business of "mea culpa," we lose sight of too many measures. They're calling this "measurement mania" We're at risk of that. You're only going to improve what you measure, so you better be careful about what you measure. Self-defeating measurement mania is very real.

Neha: You mention measurement mania and I know we're in the middle of transitioning to a new inpatient EMR. How can we use this EMR to identify measurements that are meaningful? 
Dr. Ward: We can't do this with chicken scratch and an Excel spreadsheet. You need a system, and it's one of the reasons we invested in something like Epic, but Epic is not great at this. This was my third installation of Epic at an institution-l must have done something wrong in a previous life. During my fellowship at Penn, one of my co-fellows started a project that required data collection from Epic, and it was so difficult that she changed her topic on how difficult it was to get something out of Epic. It's amazing. But it's partly because we haven't been pushing for it because it hasn't really been impacting our finances. It's the dollar that drives this from a systems standpoint. Then it changes our workflow and practices. Honestly, it can't be that doctors are doing all this stuff. We're not there yet, but eventually l'd want doctors to say, "I haven't ordered a mammogram in a year because my team does it," and the EMR can be used to make that easier.

Dr. Sorokin: Go Epic. It's the largest quality safety project that we've undertaken. We will get better at this-not in the first day, week, or month, but we will get better and how to get data out and use the EMR to its full potential. Ultimately, I'd like to get to a point where we could rely on the EMR to, say, keep track of how long patients have had central lines in for and when their dressings were last changed. It would flag when a dressing was due to be changed to reduce risk of oversight and subsequent central line infections. That is the hope, to identify gaps in patient care and predict potential complications in real time, and there's real promise with it.

Dr. Powell: The value of Epic is that it will make part of our visits easier-like ordering mammograms, flu shots, and diabetes screening-so we can spend time discussing other things that may be harder to capture. Have I engaged the family? Have I made sure that the patient understands what's going on? Have I addressed potential barriers to care? That's the value of this, to make some things easier and quicker so we can spend more time on things really important to patients and do more of the work that we actually find fulfilling.

Dr. Nash: EMRs in general can be used as a predictive tool because no one can predict patterns as easily, but something a little closer at hand is its registry function. Basic stuff like generic drug prices, screenings, HCAP scores per physician-all of this will be happening before predictive analysis and can still be pretty helpful by providing good comparative information. Everyone here was at least an A- student and is going to want to get better. If feedback is provided in a non-punitive way, I think we'll see a stampede to improve.

Neha: What challenges have come up so far and what are the biggest challenges moving forward-the next steps in the pathway?
Dr. Kane: Maybe I'll start with the big picture here. We spend $18 \%$ of our GDP on healthcare in the US. I can relate that to the budget of my own house. I've got kids I want to send to college, a mortgage I have to pay off, utilities, retirement. If I have $18 \%$ that I have to allocate to healthcare, I know I would have to squeeze out other essential elements to survive and succeed and someday retire. If you look at a traditional business model, a large fraction of my dollars earned would be spent on health insurance for my employees. We haven't moved toward healthcare reform and we have to do it quickly for businesses to thrive and for communities to thrive here.

Dr. Nash: Let me see if I can give a similar, broader perspective from the country's point of view. I was at Capitol Hill two days ago when the Republican Party proposed its own healthcare bill. The punchline is-we are only $20 \%$ of the story. Jefferson, HUP, Temple, Drexel, we're all just $20 \%$. The other $80 \%$ is comprised of social determinants, and those are often tough to handle in settings like this. If you're poor in the U.S., you're screwed. Tens of millions of people don't have health insurance. Twenty-five percent of people in Philadelphia smoke cigarettes. Forty percent of kids in public schools are obese. Poverty is the principal driver here. While we want to be efficient and not focus on cost and finances and the system, the punchline has very little to do with what goes on in these four walls. Evidence-based facts (and not alternative facts) are that countries that spend more on these social determinants have better healthcare outcomes. They are directly related.

Dr. Ward: I think it's going to be about how we interact with our community. Academic medical centers will have to touch day-to-day lives; that's one way it'll affect us. There's a global budget at Hopkins, at the Mayo ClinicHere's this much money, figure out how to make it work. If you use less, you profit. If you use more, that's on you. It really warps, in a good way, how you approach medicine. You may spend longer with the people who really need it, and you might not invest in more doctors-but rather in more care managers, social workers. We fought this tooth and nail all the way, but it's coming. We talk about HMOs and capitation: each person is worth $\$ 8$ for example. A patient can see you 15 times that year and he's still only worth \$8. It's callous, and it's not the way to run a healthcare system, but you'll want to advertise on the second floor so you don't see the people with wheelchairs or the elderly. We're going to be responsible for the patient's hospitalization and outpatient and skilled nursing facility and homecare costs. If they leave us and go to Penn, we'll be responsible for the going-to-Penn costs. How is that going to affect us? We're going to have to start looking at subspecialists. There's been an increasing microscope on how subspecialists are using dollars and how it affects overall spending. 


\section{QUESTIONS}

Dr. McKenzie: In an NPR interview, a congressman who is actually an OB/GYN from a district in Kansas pointed out what a disaster the Affordable Care Act has been for himself and his patients. There is no access to care. But he said, "People can always go to the emergency room." If we're challenged with a large proportion of people who are uninsured, how will our EDs survive?

Dr. Ward: Without getting too political here, there is a difference between access to care and true healthcare. We say we have the best healthcare in the world and people can always go to the ED, but that is not true healthcare. The $E D$ is not equipped to take care of screenings or management of chronic conditions. They'll make sure you're not dying.

Dr. Kane: The ED physicians don't want patients using the ED as their primary care. If you look at Neha's graph on countries with the lowest healthcare spending, one of the big differences between those countries and ours is that those countries provide access to PCPs for a greater portion of the day and the week. You can get to an acute care visit the same day, in the evenings and on the weekends. Not in the ED but in a primary care setting with a provider who knows them and cares about them and deals with their ongoing issues in a positive way.

Dr. Powell: The only reason we have access to the ED for primary care issues is because of legislation. We've legally made it such that EDs cannot turn any patients down, so this becomes the primary site that uninsured patients with multiple problems and nowhere to go turn. When we think about how health reform moves forward, we have to think about the structures that we've legally created and whether or not they reflect our values.

Dr. Nash: We'd bankrupt the system and force it to close. I think there's a big structural issue. Every Western developed country has three PCPs to one specialist and we're just the opposite. Temples of technology like us need to make an important decision. If we really believe that more access and more PCPs are the structural fix to this question, we need to change the environment in which we're largely training subspecialists. You've got to call it when you see it. That is a big issue.

Dr. Cohen: Is this going to lead to universal healthcare in the U.S.?

Dr. Ward: The short answer, in my personal opinion, is that universal healthcare is the only way to fix this-but it's not coming anytime soon and it may not be the right idea for the U.S. There was a great article done in the Annals of Internal Medicine looking at various countries and how healthcare came to be because of the foundation post-World War II. The U.S. got our system because, in short, we couldn't pay people more money so we had to create benefits to attract more people to their jobs. If you came and worked, you got better healthcare. We're not going to change that on a dime, and our individualist society is not going to allow us to create a single government system for everybody. They say Americans always figure out the right thing to do at the last minute when there's no other choice. I don't see this coming for the next several years.

Dr. Nash: I'd like to end on a positive note. First, how awesome to have a forum like this. Nothing like this existed certainly when I was a house officer. Secondly, we're very lucky on this campus to have a college devoted to studying this very issue. If people are interested and want to learn more, you don't have to go anywhere. We're right here. All our work is right here. We're fortunate to have an organization that has made a commitment to look at these issues, to teach and promote this. You have to look at this as a glass half-full picture.

\section{REFERENCES}

1. Anderson GF, Frogner BK. Health spending in OECD countries: obtaining value per dollar. Health Aff (Millwood). 2008:27(6):1718-1727.

2. Emanuel EJ. Where are the health care cost savings? JAMA. 2012 Jan 4:307(1):39-40. doi: 10.1001/jama.2011.1927.

3. Schroeder SA, Frist W. Phasing out fee-for-service payment. N Engl J Med. 2013:368:2029-2032. doi: 10.1056/NEJMsb1302322.

4. Laugesen MJ, Glied SA. Higher fees paid to US physicians drive higher spending for physician services compared to other countries. Health Aff (Millwood) 2011;30:1647-1656

5. Centers of Medicare and Medicaid Services. https://www.cms.gov

6. Carey K, Lin MY. Hospital Readmissions Reduction Program: Safety-Net Hospitals Show Improvement, Modifications To Penalty Formula Still Needed. Health Aff (Millwood). 2016 Oct 1;35(10):1918-1923.

7. Wasfy JH, Zigler CM, Choirat C, Wang Y, Dominici F, Yeh RW. Readmission Rates After Passage of the Hospital Readmissions Reduction Program: A Pre-Post Analysis. Ann Intern Med. 2016 Dec 27. doi: 10.7326/M16-0185.

8. Waters TM, Daniels MJ, Bazzoli GJ, Perencevich E, Dunton N, Staggs VS, Potter C, Fareed N, Liu M, Shorr RI. Effect of Medicare's nonpayment for Hospital-Acquired Conditions: lessons for future policy. JAMA Intern Med. 2015 Mar;175(3):347-54. doi: 10.1001/jamainternmed.2014.5486.

9. Koltov MK, Damle NS. Health policy basics: physician quality reporting system. Ann Intern Med. 2014 Sep 2;161(5):365-7. doi: 10.7326/M14-0786.

10. Hussey PS, Liu JL, White C. The Medicare Access And CHIP Reauthorization Act: Effects On Medicare Payment Policy And Spending. Health Aff (Millwood). 2017 Apr 1:36(4):697-705. doi: 10.1377/hlthaff.2016.0559. 